\title{
Ciclosporina A e tacrolimus: uma revisão
}

\section{Cyclosporine A and tacrolimus: a review}

Solange Cristina Garcia'; Luciana dos Santos Lopes²; Karen Lilian Schott²; Sandra Trevisan Beck'; Valdeci Juarez Pomblum ${ }^{3}$

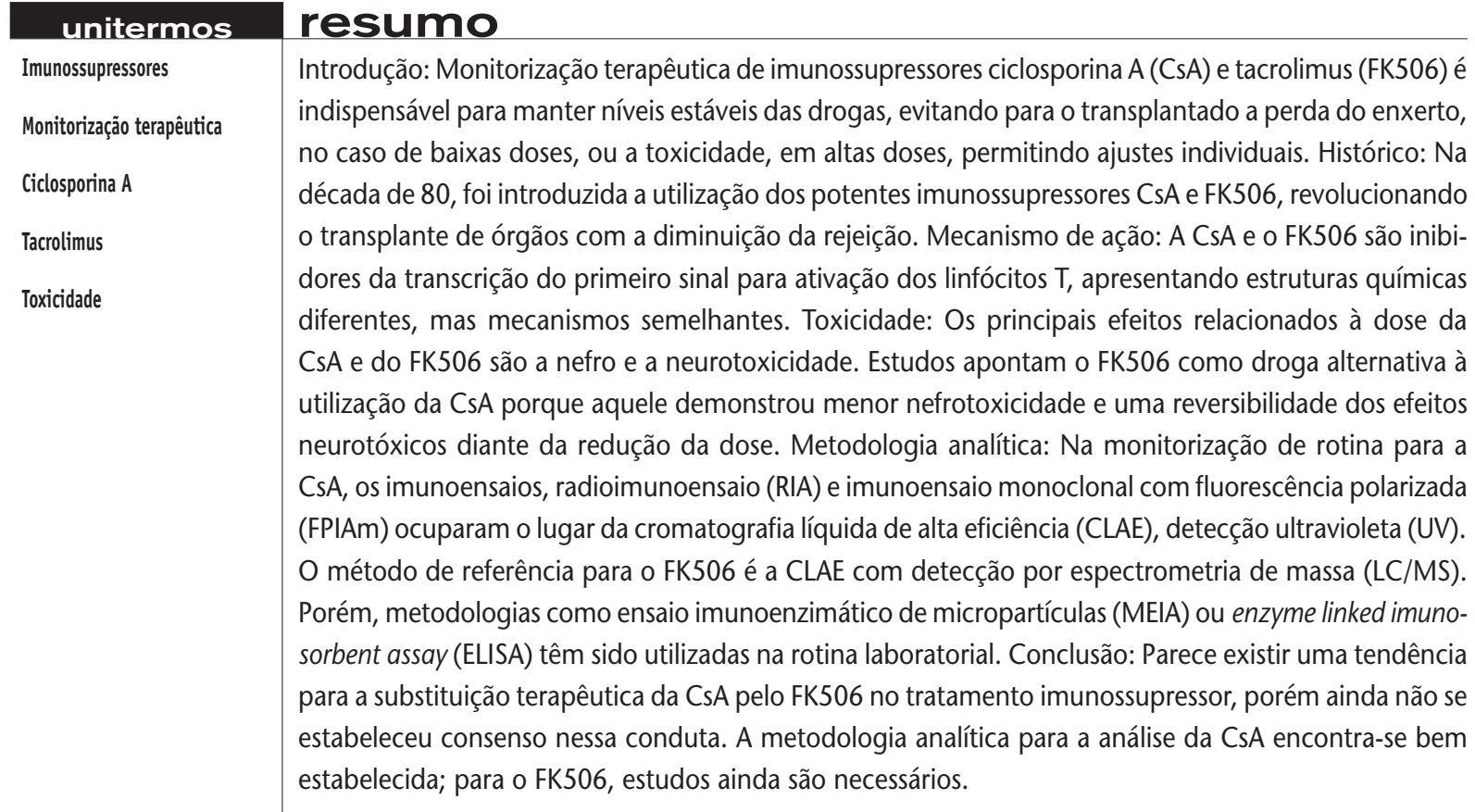

abstract

Introduction: Therapeutic monitoring of immunosuppressants cyclosporine A (CSA) and tacrolimus (FK506) is indispensable to maintain stable levels of these drugs, avoiding graft rejection in the transplanted patient in the case of low dosage, or toxicity in high dosage, and allowing monitoring of individual treatment. Background: In the 80's, the introduction of the potent immunosuppressive drugs CSA and FK506 reduced the incidence of rejection episodes after solid organ transplantation. Mechanism of action: CSA and FK506 have distinct chemical structures but similar mechanisms of action, inhibiting the transcription of the first signal for T-lymphocyte activation. Toxicity: The major side effects associated with CSA and FK506 therapies are nephrotoxicity and neurological disturbances. However, clinical studies demonstrate that FK506 is a potent alternative to CSA due to its lower nephrotoxicity and reversible neurotoxicity when the dosage is decreased. Analytical methodology: For routine monitoring of CSA, the high-performance liquid chromatography with ultraviolet detection (HPLC-UV) was replaced by the radioimmunoassay (RIA) and monoclonal antibody-based fluorescence polarization immunoassay (mFPIA). For the assessment of FK506, it is consensus that highly specific liquid chromatography/tandem mass spectrometry (LC/MS/MS) is the reference method, although the microparticle enzyme immunoassay (MEIA) and the enzyme-linked immunosorbent assay (ELISA) are currently used for routine monitoring. Conclusion: There is a tendency to substitute CSA by FK506 at immunosuppressive regimens, but this is not a consensus yet. The analytical methodology for CSA analysis is well established in the clinical laboratory, but further studies are needed to define the best methodologies for routine FK506 analysis. key words

Immunosuppressant

Therapeutic monitoring

Cyclosporine A

Tacrolimus

Toxicity

1. Doutora em Farmácia Bioquímica, Departamento de Análises Clínicas e Toxicológicas da Universidade Federal de Santa Maria (UFSM), Santa Maria-RS

2. Farmacêutica-bioquímica, Departamento de Análises Clínicas e Toxicológicas da UFSM.

3. Doutor em Medicina, Departamento de Clínica Médica da UFSM. 


\section{Introdução}

Pacientes submetidos a um tratamento prolongado com determinados medicamentos, especialmente aqueles com estreita relação entre as doses terapêutica e tóxica, necessitam ser monitorizados, quantificando-se sistemática e/ou periodicamente o fármaco ou seus metabólitos nos fluidos biológicos. Entre esses medicamentos, encontram-se os imunossupressores.

A imunossupressão, uma diminuição da atividade do sistema imunológico após o transplante de órgãos, ficou muito tempo restrita à administração empírica e não-monitorizada de drogas, como a azatioprina e a prednisona ${ }^{(1)}$.

A terapia da imunossupressão adequada é imprescindível para evitar a rejeição aguda de transplantes de órgãos, evitando assim a perda do enxerto. Porém, doses elevadas e/ou não-controladas desses medicamentos conduzem ao desenvolvimento de toxicidade ${ }^{(2)}$.

No início de 1980 foi introduzida a ciclosporina A (CsA), um imunossupressor que revolucionou o transplante de órgãos. No entanto, problemas associados à dosagem vieram à tona devido a sua pouca e imprecisa absorção, estreita janela terapêutica e seus efeitos colaterais, especialmente a nefrotoxicidade. A monitorização terapêutica se transformou numa necessidade importante ${ }^{(3)}$.

Com a disponibilização de outras drogas, como o tacrolimus (FK506) e o sirolimus, houve um aprimoramento no controle dessas terapias e as drogas imunossupressoras passaram a ser quantificadas em níveis sangüíneos ${ }^{(1)}$. A CsA e o FK506, inibidores da calcineurina, são a base da imunossupressão clínica, podendo conduzir a efeitos tóxicos, especialmente a nefrotoxicidade relacionada à $\operatorname{dose}^{(4)}$.

A CsA, potente imunossupressor, é um decapeptídeo fúngico originado do Tolypocladium inflatum gams ${ }^{(5)}$ e foi introduzido na década de 70 para provável uso em transplante de órgãos sólidos ${ }^{(6)}$. No entanto, seu uso efetivo ocorreu em 1983 no European Multicenter Trial Group e, a partir desta data, vem melhorando substancialmente a sobrevida de doentes, pacientes submetidos a transplantes cardíaco, renal, hepático, pancreático e pulmonar ${ }^{(7)}$.

O FK506, demonstrado em 1987 como opção terapêutica ${ }^{(8)}$, é um macrolídeo derivado do Streptomyces tsukubaensis ${ }^{(8)}$ e possui ação imunossupressora mais potente que a CsA. Seu uso clínico é crescente, sendo atualmente a droga base em mais de $80 \%$ dos transplantes hepáticos e $30 \%$ dos transplantes renais ${ }^{(9)}$.
Como as drogas imunossupressoras representam um problema devido à estreita faixa entre a dose terapêutica e seus efeitos tóxicos, existe um potente estímulo para monitorização biológica dessas drogas, bem como a necessidade de estudar seus parâmetros farmacocinéticos e farmacodinâmicos, fatores importantes para precisar a dose terapêutica necessária a cada paciente ${ }^{(10,11)}$, respeitando os ajustes individuais. Pois é fundamental, em pacientes transplantados, a manutenção de drogas imunossupressoras em níveis estáveis que sejam suficientemente altas para prevenir a rejeição mas, ao mesmo tempo, abaixo do limiar tóxico para minimizar efeitos como a nefro e a neurotoxicidade ${ }^{(12)}$.

\section{Histórico}

O uso combinado de agentes antiproliferativos (azatioprina) e corticóides (prednisona) foi a base de esquema imunossupressor de manutenção utilizado entre 1960 e 1986. Essas drogas produziam inadequada imunossupressão e não dispunham de monitorização sangüínea, sendo responsáveis por um grande número de rejeições agudas ${ }^{(13)}$.

O conceito de que esses episódios poderiam ser revertidos com aumento das doses de corticóide foi estabelecido em 1963 e a resposta imediata a essa terapia decorria mais do efeito antiinflamatório do que do imunossupressor ${ }^{(14)}$.

As opções terapêuticas para rejeição, como globulina antilinfocítica ${ }^{(15,16)}$ e anticorpo antilinfocitário monoclonal (CD3), precederam a introdução da CsA e reduziram a freqüência e a intensidade do processo inflamatório e da rejeição aguda quando administradas de forma profilática(17).

A grande mudança ocorreu a partir da década de 80, com a utilização da CsA como principal base da imunossupressão que, associada à azatioprina e à prednisona, configurou o esquema terapêutico de escolha, tornando-se uma clássica associação ${ }^{(18)}$.

O desenvolvimento de novas drogas imunossupressoras mais efetivas e eficazes, nesse período de 40 anos, promoveu uma redução na incidência de rejeição aguda para menos de $20 \%$, com paralelo aumento da sobrevida de $40 \%$ para próximo de $90 \%$ no primeiro ano de transplante, a maioria ultrapassando os cinco anos com função adequada $^{(19)}$.

Atualmente, os inibidores da calcineurina, a CsA e o FK506, são usados nos protocolos de imunossupressão(4). 


\section{Mecanismo de ação}

A CsA e o FK506, com base no sítio de ação imunorregulatório, são classificados como inibidores da transcrição do primeiro sinal para ativação do linfócito $T^{(20,21)}$. Possuem estrutura química diferente, porém mecanismos de ação similares $^{(4)}$.

A CsA não é uma droga citotóxica, exerce seu efeito numa população restrita de células linfóides e poupa as outras células de linhagem mielóide, conferindo-lhes certa seletividade. A ação supressora depende da formação de um complexo heterodimérico com seu receptor citoplasmático, a ciclofilina. A ciclofilina é uma peptil-propil-isomerase que se liga e inibe a atividade da fosfatase da calcineurina, resultando na inibição da expressão de genes de proteínas nucleares envolvidas na ativação celular e formação do linfócito T citotóxico. Uma dessas proteínas, o fator nuclear de células T ativado (NFAT), desloca-se para o núcleo, onde se liga à região promotora de genes interleucina 2 (IL2), interleucina 4 (IL4) e interferon gama (IFN-ã), causando a transcrição dos mesmos e a secreção das referidas citocinas. O bloqueio do NFAT é considerado, portanto, o principal efeito da $\operatorname{Cs}^{(18,22)}$.

A CsA circula associada às lipoproteínas, sendo metabolizada via citocromo $\mathrm{P} 450 \mathrm{em}$ pelo menos 25 metabólitos. Na formulação inicial, a CsA apresenta grande variação na absorção e na velocidade de metabolismo, resultando na biodisponibilidade média de $30 \%$, com variação inter e intra-individual entre $5 \%$ e $80 \%$ e meia-vida entre seis e 24 horas $^{(23)}$. A nova formulação galênica da CsA, a CsA microemulsão (Neoral), é destinada a superar os problemas de absorção da formulação standard da $\operatorname{CsA}^{(24)}$. Estudos mostraram absorção mais consistente com um alto pico de concentração e menor variabilidade individual(6, 24).

O FK506 apresenta uso clínico crescente. Embora não relacionado estruturalmente com a CsA, ele apresenta efeito farmacodinâmico similar. Entretanto mostra-se de 50 a 100 vezes mais potente em diferentes ensaios de células in vitro. Também inibe a atividade da calcineurina após se ligar a uma diferente imunofilina, a fk-binding protein isoenzyme 120 (FKBP-12), interferindo nessa via de transdução no sinal de imunoativação das células $T^{(25)}$.

As imunofilinas ligadoras do FK506 (FKBPs) se associam a receptores de glicocorticóides ou de progesterona através da ação de proteínas de fase aguda da inflamação (heat shock proteins). A ligação do FK506 aos receptores de glicocorticóides o protege contra a degradação ou inativação, promovendo a sua translocação para o núcleo e potencia- lizando a sua ligação no DNA, inibindo a transcrição de diversas citocinas inflamatórias e mimetizando o efeito dos corticóides ${ }^{(25)}$. Essa pode ser a razão farmacodinâmica pela qual a interrupção de prednisona em pacientes recebendo FK506 tem sido realizada com sucesso(26).

Muitas funções celulares são diferentemente afetadas por ambas as drogas. Porém, não há dados suficientes para concluir que os mecanismos de ação das duas drogas sejam distintos ou que esse resultado seja conseqüência de diferentes sensibilidades de diversas linhagens celulares à ação das duas drogas ${ }^{(27)}$.

Igualmente à CsA, a farmacocinética do FK506 é bastante complexa. A absorção é variável e incompleta, determinando uma biodisponibilidade que varia entre $4 \%$ e $89 \%$, sendo em média de $20 \%$ a $25 \%{ }^{(28)}$.

Diferentemente da CsA standard, a absorção do FK506 não é influenciada pela bile, o que representa uma vantagem particular dessa droga no transplante hepático ${ }^{(29)}$. Sua concentração máxima é alcançada em 30min a 60min, depois circula ligado às proteínas plasmáticas, linfócitos e hemácias e sofre metabolização hepática, resultando em mais de 15 metabólitos. A meia-vida de eliminação média é de dez horas, sendo a sua depuração maior em crianças e reduzida na presença de severa disfunção hepática ${ }^{(30)}$.

\section{Toxicidade}

O uso da CsA introduziu a monitorização farmacocinética na imunossupressão. Foi demonstrada, tanto para a CsA como para o FK506, uma correlação entre o nível residual mínimo com a eficácia e a toxicidade ${ }^{(2,31,32)}$.

A concentração elevada de CsA durante os primeiros 30 dias reduz marcadamente a incidência de rejeição aguda ${ }^{(33-35)}$, sendo que a nefrotoxicidade pode ser predita com concentrações maiores que $400 \mu \mathrm{g} / \mathrm{l}$, enquanto que a rejeição, com concentrações menores que $150 \mu \mathrm{g} /$ / $^{(36)}$. Para o FK506, recentemente um novo consenso foi publicado, sugerindo diretrizes para a monitorização da sua concentração no sangue total, considerando os níveis entre $10 \mu \mathrm{g} / \mathrm{l}$ e $15 \mu \mathrm{g} / \mathrm{l}$ na fase inicial e entre $5 \mu \mathrm{g} / \mathrm{l}$ e $10 \mu \mathrm{g} / \mathrm{l}$ após estabilização clínica(2).

Tanto a CsA como o FK506 alteram a hemodinâmica glomerular com redução da filtração( ${ }^{(37)}$, alterações histológicas caracterizadas pela presença de vacuolização tubular, fibrose intersticial e hialinose arteriolar ${ }^{(30)}$. O uso contínuo e em altas doses dessas drogas tem como limitação principal a nefrotoxicidade ${ }^{(28,38,39)}$. 
Os resultados com o FK506 em transplantes hepáticos e renais comprovam sua elevada eficácia na prevenção da rejeição aguda, porém também há demonstração de elevada incidência de efeitos colaterais como a nefro e a neurotoxicidade.

Efeitos próprios da CsA e clinicamente relevantes são severa hipertensão arterial, síndrome urêmica hemolítica induzida pela CSA, hipercolesterolemia, severa hipertricose e hipertrofia gengival, além de hirsutismo e diabetes ${ }^{(40-42)}$. Entretanto, a incidência de alguns tipos de neurotoxicidade, distúrbios no metabolismo da glicose, diarréia, pruridos e alopécia pode ser maior no tratamento com o FK506 ${ }^{(43)}$. Em trabalho realizado sobre o metabolismo da glicose em transplantados renais que receberam FK506 versus CsA, demonstrou-se que após três a seis meses havia uma tendência ao aumento da resistência periférica à insulina, referente a um significativo aumento da glicose de jejum. Após seis meses, não havia significante alteração em nenhum dos parâmetros do metabolismo da glicose, indicando que o uso há longo tempo, com ambos os imunossupressores, não causa crônica ou cumulativa toxicidade pancreática ${ }^{(4)}$.

Em estudo comparativo entre as duas drogas, após duas semanas, concluiu-se que a CsA afeta mais a hemodinâmi$\mathrm{ca}$, a pressão arterial, predispondo mais o transplantado a uma falência renal(45). Embora o FK506 esteja associado a muitas formas de nefrotoxicidade $(2,4,9,10,39)$, existem alguns precedentes na literatura associando a melhoria da função renal após a substituição da CsA pelo FK506 (46). Estudos sugerem um significativo decréscimo de creatinina em seis meses após essa mudança( ${ }^{(9)}$.

A CsA tende a estar mais associada com a incidência de hiperlipidemia e hipertensão ${ }^{(45)}$. Em relação à hiperlipidemia, pode-se dizer que esses efeitos não são importantes em relação à falência cardiovascular mas estão associados ao desenvolvimento da nefropatia crônica no uso da CsA como imunossupressor ${ }^{(47)}$. Em estudos comparativos, o FK506 não possui esses efeitos ${ }^{(39,48,49)}$. Na substituição da CsA pelo FK506, foi observada redução da hiperlipidemia e, ao mesmo tempo, o não-aparecimento de casos de hipertensão arterial, diabetes e lapsos de memória ${ }^{(9)}$.

O FK506 pode ser o imunossupressor de escolha para reduzir o desconforto gástrico e minimizar os riscos relatados pela instabilidade através dos níveis de drogas imunossupressoras. Em relato de caso em uma paciente receptora de pulmão, a substituição da CsA pelo FK506 foi bem-sucedida para corrigir a disfunção motora gástrica ${ }^{(50)}$.

A neurotoxicidade tem sido relatada no tratamento da imunossupressão com CsA e FK506. As complicações neurológicas parecem estar, com maiores efeitos, predominantemente associadas ao $\mathrm{FK} 506^{(51)}$. No entanto, outros estudos descrevem uma melhora ( $75 \%$ e 100\%, respectivamente) dos efeitos neurológicos, os quais foram associados à substituição da CsA pelo FK506 ${ }^{(46,52)}$.

A leucoencefalopatia fatal é uma rara complicação relativa ao uso de inibidores da calcineurina, especialmente em transplantados renais e hepáticos. Em relato de caso, uma mulher de 37 anos desenvolveu essa patologia 12 semanas após o transplante cardíaco, fazendo uso do FK506. Indícios sustentam a hipótese de que essa neurotoxicidade está associada à diminuição da barreira hematoencefálica mas, com a diminuição da dose, no entanto, houve reversibilidade do quadro, não sendo necessária a suspensão do FK506 ${ }^{(53)}$.

Outros estudos mostram diferentes vantagens no uso do FK506. Em 232 transplantados renais, o tratamento com FK506 comparado a Neoral mostrou uma significativa melhora no perfil dos riscos cardíacos e da função renal. Em relação ao tempo de sobrevida, considerando seis anos, no tratamento com o FK506 foi maior do que com a CsA $(81 \% \text { contra } 60 \%)^{(54)}$.

\section{Metodologia analítica}

\section{Amostra biológica}

Para a quantificação da CSA e do FK506, é possível utilizar diferentes fluidos biológicos: soro, plasma e sangue total $(2,4,6,55,56,58-60)$. Nesse caso, o anticoagulante EDTA é empregado para a monitorização da $\operatorname{CsA}^{(6,58,61)}$ e do FK506 ${ }^{(59)}$. Devido à ligação do fármaco, em alta percentagem, às hemácias e às lipoproteínas, recomenda-se sua determinação em sangue total|(62).

A conservação das amostras biológicas para a monitorização da CsA pode ser de um período máximo de três dias, a $4^{\circ} \mathrm{C}$, a até quatro meses, a $-20^{\circ} \mathrm{C}^{(61)} \mathrm{e}$, para a monitorização do $\mathrm{FK} 506$, a uma temperatura $-70^{\circ} \mathrm{C}$ até o momento da análise ${ }^{(59)}$.

Para monitorização da CsA, o procedimento que melhor parece estimar a exposição à droga é a realização de colheitas de amostras sangüíneas que permitam a obtenção de uma curva com um total de 6 pontos em 12 horas. Porém esse método é limitado pelo custo e pela necessidade de múltiplas amostras de sangue para cada ponto da curva ${ }^{(62)}$. Uma única análise da concentração após $12 \mathrm{~h}$ da última dose também é preconizada ${ }^{(9)}$. No entanto, estudos recentes apontam que a determinação da CSA durante a fase de 
absorção (0-4h) pode oferecer um melhor prognóstico da eficiência imunossupressora ${ }^{(4,61)}$. Para a terapia com Neoral, a avaliação da concentração duas horas após a dose parece ser uma alternativa eficiente. Porém, a alta concentração da droga, presente nesse período, normalmente exige uma diluição da amostra antes da análise. Isso ocorre devido à possibilidade de a concentração da CsA presente na amostra encontrar-se mais elevada que o valor do ponto mais alto da curva de calibração( ${ }^{(2,4)}$.

O grande problema na monitorização do FK506 é o estabelecimento do tempo apropriado e consensual no controle terapêutico(2).

\section{Tratamento da amostra biológica}

Amostras de sangue total sofrem uma etapa de separação prévia às análises. Hemólise seguida de extração líquidolíquido é empregada para a monitorização sangüínea da CsA, utilizando a técnica de imunoensaio por multiplicação enzimática (EMIT) e cromatografia líquida de alta eficiência (CLAE) que necessita, ainda, de extração em fase sólida ${ }^{(6,}$ 59). Um pré-tratamento da amostra sangüínea é necessário também no emprego do imunoensaio monoclonal com fluorescência polarizada (FPIAm) e no ensaio imunoenzimático de micropartículas (MEIA), diferentemente do prétratamento necessário para analisar com o cloned enzyme donor immunoassay (CEDIA), pois uma etapa de separação não é necessária(6).

A quantificação do FK506 necessita pré-tratamento e a extração líquido-líquido é fundamental para a metodologia utilizando $\operatorname{CLAE}^{(56,59)}$.

\section{Técnicas analíticas}

A técnica considerada referência tanto para a CsA como para o FK506 ainda parece ser a CLAE com detecção ultravioleta (UV) e tandem espectrometria de massa MS/MS, respectivamente ${ }^{(2,4,6,59)}$. A CLAE foi a primeira técnica utilizada para monitorização dessas drogas. Porém é de difícil automação e de custos elevados ${ }^{(63)}$, razão pela qual um levantamento realizado em 35 centros mostrou que $86 \%$ dos laboratórios usavam imunoensaios para a monitorização da $\mathrm{CsA}^{(6)}$. Atualmente, existem seis técnicas analíticas em uso para a monitorização da CsA e ainda várias outras em desenvolvimento ${ }^{(61,64)}$.

Isso se deve, provavelmente, aos avanços observados no desenvolvimento de ensaios para a monitorização de drogas. Em 1990 surgiu o método FPIAm, alternativo ao radioimunoensaio (RIA). O FPIAm utiliza como mar- cador a fluoresceína, não apresentando os problemas de manipulação, descarte e validade dos reagentes que ocorriam com o RIA. O mesmo acontece com os outros ensaios enzimáticos que, dependendo do substrato utilizado na reação, permitem a leitura final através da medida da absorbância espectrofotométrica - enzymelinked immunosorbent assay (ELISA), EMIT - ou a emissão de luz (MEIA, FPIAm). A maioria dos métodos baseia-se na competição da droga presente nos fluidos biológicos com a droga marcada com fluoresceína (FPIAm), com a enzima glicose-6-fosfato desidrogenase (EMIT) ou com a fosfatase alcalina (MEIA), que atuam sobre o substrato correspondente. A concentração da droga nas amostras biológicas será inversamente proporcional ao sinal emitido ao término da reação( ${ }^{(65)}$.

Comercialmente, esses métodos são encontrados em ensaios desenvolvidos pelo laboratório Abbott nos equipamentos TDx (FPIAm), AxSYm (FPIAm), IMx (MEIA II) e pela companhia Dade-Behring (EMIT 2000).

Esses ensaios apresentam diferentes especificidades $\mathrm{e}$ são utilizados para a monitorização terapêutica da CsA e do FK506 na clínica de transplantes, tendo sua acurácia e sua especificidade avaliadas por diferentes estudos para melhor conhecimento e avaliação dos resultados $(6,55,56,60,61,64)$.

Os imunoensaios para monitorar a CSA mostram ainda um considerado desvio quando comparados com a CLAE, em particular com amostras de receptores vivos ${ }^{(2)}$.

O anticorpo monoclonal baseado no FPIAm para CsA da Abbott tem sido adaptado para análises no AxSYM. O novo AxSYM FPIAm tem a vantagem de estabilidade nas curvas de calibração e boa praticidade ${ }^{(2)}$. Em recente avaliação, resultados comparativos foram obtidos entre essa metodologia e CLAE utilizando-se amostras de pacientes infantis ${ }^{(33)}$.

Em comparação com o EMIT, o ensaio FPIAm mostra uma alta reação cruzada com metabólitos da CsA. A média de desvio entre os dois métodos ficou por volta de $15 \%{ }^{(2)}$.

O problema dessas variações parece estar no estado individual de imunossupressão de cada paciente. A partir desse problema, há estudos que direcionam a dosagem para uma medida na atividade da calcineurina fosfatase em células mononucleares do sangue periférico dos pacientes que fazem uso de CsA. Em estudo com 62 transplantados renais tratados com CsA, média de $180 \pm 54 \mu \mathrm{g} / \mathrm{l}$, a atividade da calcineurina fosfatase foi detectada, mas estava reduzida em $50 \%$ quando comparada com controles em dosagens 
normais. Com isso, foi constatado que não há uma relação entre a atividade da calcineurina-fosfatase e a CsA, sugerindo que o nível de CSA está limitado na avaliação da eficácia imunossupressora(2).

Segundo Lake Louise Consensus Conference (1995), o mais específico dos métodos em comparação com a cromatografia líquida de alta eficiência foi o EMIT, seguido do CEDIA e FPIAm (AxSYm) ${ }^{(62,66)}$.

O ensaio monoclonal FPIAm (TDx) foi o que menos apresentou especificidade entre os analisados. Essas considerações são de extrema importância na monitoração da ciclosporina em transplante clínico, influenciando diretamente a medida das concentrações que serão administradas nos pacientes ${ }^{(3)}$. Porém, estudo recente comparando os resultados da CsA obtidos pelos métodos EMIT 2000 e FPIAm (TDx) mostrou excelente correlação. A metodologia EMIT mostrou-se vantajosa em relação a custos e adequação da rotina para o processamento das $\operatorname{amostras}^{(67)}$.

Em consenso documentado em 1995, entre os métodos desenvolvidos para quantificação do FK506 no sangue total, a utilização da CLAE com MS/MS foi considerada método de referência ${ }^{(55-57)}$. Na rotina, a monitoração é feita através de kits comerciais com anticorpos monoclonais que incluem o ensaio do FK506 pelos métodos imunoenzimáticos ELISA

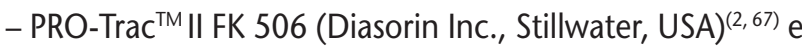
MEIA (IMx), sendo este último mais vantajoso em termos de custo e rapidez ${ }^{(67)}$.

O método MEIA original I tem detecção limite de 5ìg/l, porém há um segundo ensaio, MEIA II, que detecta limites de $2 i \mathrm{ig} /\left({ }^{(53)}\right.$.

Quanto à especificidade dos métodos ELISA e MEIA, foram feitos vários estudos em diferentes centros comparando-se com CLAE MS/MS ou CLAE detecção com espectrometria de massa e encontrou-se desvio positivo quando usando ELISA de 17\%, comparando os resultados de medidas do FK506 em pacientes transplantados ${ }^{(55)}$.

Outro estudo compara o método MEIA I e a CLAE MS/ MS e tem desvio positivo de $3 \%$ com excelente coeficiente de correlação ${ }^{(56)}$.

Em outra investigação, agora com MEIA II em 104 amostras de crianças, a concentração determinada com esse método ficou por volta de $20 \%$ acima da observada com CLAE MS/MS, embora a correlação dos dois procedimentos tenha sido considerada excelente ${ }^{(59)}$.

Estudos adicionais têm comparado os mesmos imunoensaios e mostraram baixa correlação( ${ }^{(53,68)}$.
Essa positividade parcial com métodos MEIA e ELISA está relacionada a severas reações cruzadas entre metabólitos do FK506 e anticorpos monoclonais ${ }^{(9)}$. Uma possibilidade de direcionar o problema seria a formação de um pentâmero. O ensaio, que inclui a formação deste pentâmero, faz a quantificação do FK506 mais aqueles metabólitos que podem estar ligados com FK-BP12 e o complexo cálciocalmodulina-calcineurina ${ }^{(2)}$.

Assim, em casos de reação cruzada com metabólitos na metodologia ELISA, a elaboração desse ensaio pentamérico forneceu método alternativo para medir o estado de imunossupressão dos pacientes ${ }^{(59,69)}$.

\section{Conclusão}

A introdução dos imunossupressores na clínica revolucionou o transplante de órgãos com a diminuição das rejeições e o aumento da vida-média do enxerto transplantado, aumentando o tempo de vida do receptor.

A toxicidade dessas drogas tornou-se um problema, e a monitorização terapêutica dos imunossupressores passou a ocupar um lugar imprescindível no bom prognóstico dos procedimentos pós-enxerto de órgãos.

O controle terapêutico de medicamentos como a CsA e o FK506, devido a sua estreita janela terapêutica, auxilia nos ajustes das doses individuais para os receptores, respeitando as particularidades do tecido transplantado, e é aliado no prolongamento da vida após o transplante.

A dose e o melhor tratamento imunossupressor devem ser adotados e ajustados individualmente, preconizando o êxito na adoção da substituição da CsA pelo FK506, principalmente para diminuir efeitos tóxicos.

$\mathrm{Na}$ colheita da amostra biológica, muitos parâmetros devem ser observados (anticoagulante, tempo e condições de conservação e tempos ideais da colheita). A CsA apresenta muitos estudos relacionados à farmacocinética, e o tempo de duas horas após a última dose parece ser adotado em muitos centros. Para o FK506, há um problema no estabelecimento do melhor tempo de colheita.

A escolha da melhor metodologia também é discutível, pois na rotina os métodos imunológicos são os mais adotados por sua praticidade e sua disponibilidade laboratorial em comparação com a utilização de métodos cromatográficos, que são considerados métodos de referência para a monitorização da CsA e do FK506, porém trabalhosos e onerosos. 


\section{Referências}

I. ELLENHORN, J. D. et al. Activation of human T cells in vivo following treatment of transplant recipients with OKT3. Transplantation, v. 50, n. 4, p. 608-12, 1990.

2. OELLERICH, M. et al. Therapeutic drug monitoring of cyclosporine and tacrolimus. Clin Biochem, v. 31, n. 5, p. 309-16, 1998

3.MAHALATI,K. et al. Neoral monitoring by simplified sparse sampling area under the concentration-time curve: its relationship to acute rejection and cyclosporine nephrotoxicity early after kidney transplantation. Transplantation, v. 68, n. I, p. 55-62, 1999.

4. ARMSTRONG, V. W.; OELLERICH, M. New developments in the immunosuppressive drug monitoring cyclosporine, tacrolimus, and azathioprine. Clin Biochem, v. 34, n. I, p. 9-16, 200|.

5. BOREL, J. F.; KIS, Z. L. The discovery and development of cyclosporine (Sandimmune). Transplant Proc, v. 23, n. 2, p. |867-74, 199|.

6. SCHÜTZ, E. et al. Cyclosporine whole blood immunoassays (AXSYM, CEDIA, and Emit): a critical overview of performance characteristics and comparison with HPLC. Clin Chem, v. 44, n. 10, p. 2158-64, 1998.

7. MCMILLAN, M. A. Clinical pharmacokinetics of cyclosporin. Pharmac Ther, v. 42, n. I, p. 135-56, 1989.

8. KINO,T.et al. FK-5006, a novel immunosuppressant isolated from a Streptomyces. II. Immunosuppressive effect of FK-5006 in vitro. Antibiot (Tokyo), v. 40, p. 1256-65, 1987.

9. SELZNER, N. et al. Conversion from cyclosporine to FK506 in adult liver transplant recipients: a combined North American and European experience. Transplantation, v. 72, n. 6, p. 106|-5, 2001.

10. KAHAN, B. D. Individualization of cyclosporine therapy using pharmacokinetic and pharmacodynamic parameters. Transplantation, v. 40, n. 5, p. 457-76, 1985.

II. KAHAN, B. D. et al. Demographic factors affecting the pharmacokinetics of cyclosporine estimated by radioimmunoassay. Transplantation, v. 4I, n. 4, p. 459-64, 1986.

12.VERLEDEN, G. M. et al. Successful conversion from cyclosporine to tacrolimus for gastric motor dysfunction in a lung transplant recipient. Transplantation, v. 73, n. 12, p. 1974-6, 2002.

13. SAITOVITCH, D. et al. Biópsia percutânea em rim transplantado: indicações, complicações e análise prospectiva de sua influência sobre a evolução do enxerto e do paciente. J Bras Nefrol, v. 13, n. I, p. 12-8, 1991.

14.STARZL,T.E.; MARCHIORO,T.L;;WADDELL,W. R. The reversal of rejection in human renal homographs with subsequent development of homographic tolerance. Surg Gynecol Obstet, v. I17, p. 385-95, 1963.

15. KONOMI, K. et al. Immunosuppression with antilymphocyte globulin in clinical renal transplantation. Surg Forum, v. 19 , p. 194-5, 1968.

16. FILO, R. S.; SMITH, E. J.; LEAPMAN, S. B. Therapy of acute cadaveric renal allograft rejection with adjunctive antithymocyte globulin. Transplantation, v. 30, n. 6, p. 445-9, 1980.

17. COSIMI, A. B. et al. Use of monoclonal antibodies to T-cell subsets for immunologic monitoring and treatment in recipients of renal allografts. $N$ Engl J Med, v. 305, n. 6, p. 308-|4, 1981.

18. KAHAN, B. D. Cyclosporine. N Engl J Med, v. 321, n. 25, p. 1725-38, 1989.

19. HARIHARAN, S. et al. Improved graft survival after renal transplantation in the United States, 1988 to 1996. N Engl J Med, v. 342, n. 9, p. 605-12, 2000.

20. GRAHAM, R. M. Cyclosporine: mechanism of action and toxicity. Cleve Clin J Med, v. 6I, n. 4, p. 308-13, 1994.

21. FOXWELL, B. M.; WOERLY, G.; RYFFEL, B. Inhibition of interleukin 4 receptor expression on human lymphoid cells by cyclosporin. Eur J Immunol, v. 20, n. 5, p. | |85-6, 1990.

22. FRUMAN, D. A. et al. Calcineurin phosphatase activity in $T$ lymphocytes is inhibited by FK 506 and cyclosporin A. Proc Natl Acad Sci USA, v. 89, n. 9, p. 3686-90, 1992.

23. MYERS, B. D. et al. Cyclosporine-associated chronic nephropathy. N Engl J Med, v. 3 I I, p. 699-05, 1984.

24. HIGGINS, R. M. et al. Conversion from tacrolimus to cyclosporine in stable renal transplant patients: safety, metabolic changes, and pharmacokinetic comparison. Transplantation, v. 69, n. 8, p. 1736-39, 2000.

25.THOMSON, A. W.; BONHAM, C. A.; ZEEVI, A. Mode of action of tacrolimus (FK506): molecular and cellular mechanisms. Ther Drug Monit, v. 17, n. 6, p. 584-9I, 1995.

26. CHAKRABARTI, P. et al. Outcome after steroid withdrawal in paediatric renal transplant patients receiving tacrolimusbased immunosuppression. Transplantation, v. 70, n. 5, p. 760-64, 2000.

27. PLOSKER, G. L.; FOSTER, R. H. Tacrolimus: a further update of its pharmacology and therapeutic use in the management of organ transplantation. Drugs, v. 59, n. 2, p. 323-89, 2000.

28. BARROS, E. J. et al. Glomerular hemodynamics and hormonal participation on cyclosporine nephrotoxicity. Kidney Int, v. 32, n. I, p. 19-25, 1987.

29. VENKATARAMANAN, R. et al. Clinical pharmacokinetics of tacrolimus. Clin Pharmacokinet, v. 29, p. 404-30, 1995.

30. SPENCER, C. M.; GOA, K. L.; GILLIS, J. C. Tacrolimus: an update of its pharmacology and clinical efficacy in the management of organ transplantation. Drugs, v. 54, n. 6, p. 925-75, 1997.

31. IRSCHIK, E. et al. Cyclosporin blood levels do correlate with clinical complications. Lancet, v. 2, n. 8404, p. 692-3, 1984.

32. KLINTMALM, G. et al. Cyclosporine plasma levels in renal transplant patients. Association with renal toxicity and allograft rejection. Transplantation, v. 39, n. 2, p. I32-7, 1985.

33. SALOMON, D. et al. A retrospective analysis of late renal graft function: correlation with mean cyclosporine levels and lack 
of evidence for chronic cyclosporine toxicity. Transplant Proc, v. 23, n. I, Pt 2, p. 1018-9, 1991.

34. BASADONNA, G. P. et al. Early versus late acute renal allograft rejection: impact on chronic rejection. Transplantation, v. 55, n. 5, p. 993-5, 1993.

35. NANKIVELL, B. J.; HIBBINS, M.; CHAPMAN, J. R. Diagnostic utility of whole blood cyclosporine measurements in renal transplantation using triple therapy. Transplantation, v. 58, n. 9. p. 989-96, 1994.

36.TEDESCO, H. S. et al. Otimização do uso da CsA em transplante renal. Rev Assoc Med Bras, v. 38, n. 183-94, 1992.

37. SOUZA, E. R. et al. Acute effects of FK 506 on glomerular hemodynamics. Transplant Proc, v. 24, n. 6, p. 3082, 1992.

38. REMUZZI, G.; PERICO, N. Cyclosporine-induced renal dysfunction in experimental animals and humans. Kidney Int Suppl, v. 52, p. 70-4, 1995.

39. PIRSCH, J. D. et al. A comparison of tacrolimus (FK506) and cyclosporine for immunosuppression in cadaveric renal transplantation. FK506 kidney transplant study group. Transplantation, v. 63, n. 7, p. 977-83, 1997.

40. FRIEMANN, S. et al. Improvement of nephrotoxicity, hypertension, and lipid metabolism after conversion of kidney transplant recipients from cyclosporine to tacrolimus. Transplant Proc, v. 30, n. 4, p. 1240-2, 1998.

4I. FRIEMANN, S. et al. Conversion to tacrolimus in hyperlipidemic patients. Transplant Proc, v. 3I, 7A, 4I S-43S, 1999.

42. THORP, M. et al. The effect of conversion from cyclosporine to tacrolimus on gingival hyperplasia, hirsutism, cholesterol. Transplantation, v. 69, n. 6, p. 1218-20, 2000.

43. SCOTT, L. J. et al. Tacrolimus: a further update of its use in the management of organ transplantation. Drugs, v. 63, n. 12, p. 1247-97, 2003.

44.Van DUIJNHOVEN, E. M. et al. Glucose metabolism in the first three years after renal transplantation in patients receiving tacrolimus versus cyclosporine-based immunosuppression. J Am Soc Nephrol, v. I3, n. I, p. 213-20, 2002.

45. KLEIN, I. H. H. T. et al. Different effects of tacrolimus and cyclosporine on renal hemodynamics and blood pressure in healthy subjects. Transplantation, v. 73, n. 5, p. 673-4, 2002

46. PRATSCHKE, J. et al. Treatment of cyclosporine-related adverse effects by conversion to tacrolimus after liver transplantation: long-term results. Transplant Proc, v. 30, n. 4, p. 1419-21, 1998.

47. LIGTENBERG, G. et al. Cardiovascular risk factors in renal transplant patients: cyclosporine A versus tacrolimus. J Am Soc Nephrol, v. I2, p. 368-73, 200 I.

48. FRIEMANN, S. et al. Improvement of nephrotoxicity, hypertension, and lipid metabolism after conversion kidney transplant recipients from cyclosporine to tacrolimus. Transplant Proc, v. 30, n. 4, p. 1240-2, 1998.

49. McCUNE, T. R. et al. Effects of tacrolimus on hyperlipidemia after successful renal transplantation: a southeastern organ procurement foundation multicenter clinical study. Transplantation, v. 65, n. I, p. 87-92, 1998.

50. PIRSCH, J. et al. Coadministration of tacrolimus and mycophenolate mofetil in stable kidney transplant patients, pharmacokinetics and tolerability. J Clin Pharmacol, v. 40, n. 5, p. 527-32, 2000.

5 I. JORDAN, M. L. et al. FK506 "rescue" for resistant rejection of renal allografts under primary cyclosporine immunosuppression. Transplantation, v. 57, n. 6, p. 860-5, 1994.

52. GONZÁLEZ-PINTO, J. et al. Usefulness of the switch to tacrolimus in liver transplantation. Transplant Proc, v. 31 , p. 2425-6, 1999.

53. KACZMAREK, l. et al. Impairment of the blood-brain barrier can result in tacrolimus-induced reversible leucoencephalopathy following heart transplantation. Clin Transplant, v. 17, n. 5, p. 469-72, 2003.

54. JUREWICZ, W. A. Tacrolimus versus cyclosporin immunosuppression: long-term outcome in renal transplantation. Nephrol Dial Transplant, v. 18, suppl. I, p. 7-। I, 2003.

55. TAYLOR, P. J. et al. Sensitive, specific quantitative analysis of tacrolimus (FK506) in blood by liquid chromatographyelectrospray tandem mass spectrometry. Clin Chem, v. 42, n. 2, p. 279-85, 1996.

56.ZHANG, Q.; SIMPSON, J.;ABOLENEEN, H. I.A specific method for the measurement of tacrolimus in human whole blood by liquid chromatography/tandem mass spectrometry. Ther Drug Monit, v. 19, n. 4, p. 470-6, 1997.

57.JUSKO,W.J. et al. Consensus document: therapeutic monitoring of tacrolimus (FK-506). Ther Drug Monit, v. 17, n. 6, p. 60614, 1995.

58. BOTTINI, P.V. et al. Monitoramento dos níveis de ciclosporina em sangue total em transplantes renais. Rev Assoc Med Bras, V. 44, n. 3, p. 176-8, 1998.

59. ARMSTRONG, V. W. et al. Modified pentamer formation assay for measurement of tacrolimus and its active metabolites: comparison with liquid chromatographytandem mass spectrometry and microparticle enzymelinked immunoassay (MEIA-II). Clin Chem, v. 44, n. 12, p. 25।6-23, 1998.

60. PRZEPIORKA, D. et al. Relationship of tacrolimus whole blood levels to efficacy and safety outcomes after unrelated donor marrow transplantation. Biol Blood Marrow Transplant, v. 5, n. 2, p. 94-7, 1999.

6I. STEIMER, W. Performance and specificity of monoclonal immunoassay for cyclosporine monitoring: how specific is specific? Clin Chem, v. 45, n. 3, p. 37I-8I, 1999.

62. KAHAN, B. D. et al. Consensus document: Hawk's Cay meeting on therapeutic drug monitoring of cyclosporine. Clin Chem, v. 36, n. 8, Pt I, p. I510-6, 1990.

63. McBRIDE, J. H. et al. Measurement of cyclosporine by liquid chromatography and three immunoassays in blood from liver, cardiac, and renal transplant recipients. Clin Chem, v. 38, n. II, p. 2300-6, 1992.

64. HOLT, D.W. et al. New approaches to cyclosporine monitoring raise further concerns about analytical techniques. Clin Chem, v. 46, n. 6, p. 872-4, 2000.

65. SANCHEZ, M. C. A. Testes sorológicos. In: FERREIRA, A. W:; ÁVILA, S. M. Diagnóstico laboratorial das principais doenças infecciosas e auto-imunes. 2 ed. Rio de Janeiro: Guanabara Koogan, 200 I. Cap. 2, p. 9-48. 
66. OELLERICH, M. et al. Lake Louise Consensus Conference on cyclosporin monitoring in organ transplantation: report of the consensus panel. Ther Drug Monit, v. 17, n. 6, p. 642-54, 1995

67. DIETEMANN, J. et al. Comparison of ELISA method versus MEIA method for daily practice in the therapeutic monitoring of tacrolimus. Nephrol Dial Transplant, v. 16, p. 2246-9, 2001.
68. GONSCHIOR, A. K. et al. Tacrolimus (FK506) metabolite patterns in blood from liver and kidney transplant patients. Clin Chem, v. 42, n. 9, p. 1426-32, 1996.

69. TAMURA, K. et al. Interaction of tacrolimus (FK506) and its metabolites with FKBP and calcineurin. Biochem Biophys Res Comm, v. 202, n. I, p. 437-43, 1994. 